\title{
Da tradução de "Uma sociologia em ato dos intelectuais: os combates de Karl Kraus", de Michael Pollak
}

Letícia Borges Nedel'

Nos mais de vinte e cinco anos decorridos desde o prematuro desaparecimento de Michael Pollak, não faltaram ocasióes editoriais em que companheiros de geraçáo, herdeiros e admiradores ilustres reverenciaram a memória do colega e autor, dono de uma produçáo abundante, caudatária das causas que defendeu em vida. Multiversa como as «feridas» em torno das quais articulava seu interesse de pesquisa pelas dinâmicas identitárias, especialmente pela gestão das identidades sob condiçóes extremas, a produção escrita deixada pelo intelectual austríaco compóe-se de dezenas de textos cujo traço característico unanimemente reconhecido pelos comentadores é o vínculo estrutural, material e afetivo que mantém com a experiência de vida do pesquisador.

Entre 1971, ano em que se transferiu para Paris para cursar o doutorado na École Pratique des Hautes Études, e 1992, quando aos 43 anos, já reconhecido internacionalmente, morre na condição que tomava por objeto de sua própria prática investigativa sobre os impactos sociais da epidemia de Aids, Pollak levou ao limite do realizável a sociologia autorreflexiva da qual se fizera herdeiro. Dotada de grande capacidade de permanência, ela deve sua vitalidade ao refinamento metodológico com que procedeu ao delicado trabalho de "tornar compreensivo o inaceitável", como no admirável artigo Des Mots qui Tuent, cujo título bem expressa o seu entendimento do conhecimento como uma forma de intervenção no mundo.

1 Professora do Programa de Pós-Graduação em História da Universidade Federal de Santa Catarina (UFSC).

$($ (c)) EY
Direito autoral e licença de uso: Este artigo está licenciado sob uma Licença Creative Commons. Com essa licença você pode compartilhar, adaptar, para qualquer fim, desde que atribua a autoria da obra, forneça um link para a licença, e indicar se foram feitas alterações. 
Já qualificado como passeur (BÉDARIDA, 1993) similar ao estrangeiro de Georg Simmel do qual se apropriou para referir o confinamento relativo das sociabilidades homossexuais (BASTIN, 2008), Pollak foi, por força das suas circunstâncias, um poliglota capaz de transpor culturas e disciplinas. Transitou com igual desenvoltura entre as sociologias francesa e alemã, a história social da cultura praticada no âmbito de uma história do tempo presente e os estudos sobre a regulação pública da gestão de riscos tecnológicos conduzidos nos EUA na década de 1970. Em vinte anos de carreira, desenvolveu trabalhos que vão da sociologia da ciência e da técnica para uma história política da memória, com pesquisa intensiva em arquivos e incursóes importantes pelo campo da história oral. Esse repertório temático foi sendo composto à medida que abastecia a sua vontade de cobrir, num mesmo movimento intelectual, a multidimensionalidade dos fenômenos, a interdependência dos processos e a heteronomia do investigador.

$\mathrm{O}$ artigo traduzido no presente número da Revista Política \& Sociedade é produto desse modus operandi. Nele, o autor se propóe a analisar as batalhas que o dramaturgo e humorista austríaco Karl Kraus solitariamente travou contra o fisiologismo da imprensa, dos intelectuais e dos artistas de seu tempo, entre as vésperas da primeira e da segunda guerras mundiais. A análise de Pollak sobre os combates de Kraus abre um caminho interpretativo diferente de tentativas anteriores nas quais pesquisadores buscavam sistematizar, a partir de sua produçáo escrita, uma suposta teoria purista da língua. Diferente disso, a Pollak interessa pensar essa produçáo como uma sociologia-ação reveladora do jogo intelectual em suas relaçóes com o poder, e também como um indicador da crise do campo intelectual austríaco, submetido à reestruturação do mercado de bens culturais sob forte demanda social. O trabalho participa de uma via reflexiva que, por cerca de dez anos, manteve-se no centro dos investimentos intelectuais do sociológo - qual seja, a Viena do entresséculo XIX-XX e, a partir dela, a análise das consequências socioculturais de grandes acontecimentos da política, como a dissolução da Áustria-Hungria e a Primeira Guerra Mundial. Publicado na $A R S S$, em 1981, o artigo veio na sequência de outro, publicado na mesma revista, em 1979, dedicado aos ajustes intelectuais e científicos que a imigração para os EUA impôs à carreira acadêmica de mais outro 
conterrâneo seu. Esse artigo, intitulado Paul F. Lazarsfeld: fundador de uma multinacional cientifica foi traduzido no número anterior a este da Revista Politica \& Sociedade, que, mais uma vez, toma a iniciativa de ampliar o conhecimento que se tem da obra do autor no Brasil.

Diferente do aclamado Des Mots qui Tuent, publicado em 1982, de Le Témoignage e La Gestion de L'Indicible, ambos de 1986, nos quais Pollak articula a abordagem do conteúdo dos testemunhos de sobreviventes dos campos de concentração às suas condições de enunciação, ou ainda dos livros que o fizeram reconhecido, como Vienne 1900, de 1984, e o magistral L'Éxperience Concentrationnaire, de 1990, Uma Sociologia em Ato dos Intelectuais: os combates de Karl Kraus não conta com mais do que cinco citações relatadas pelo Google Acadêmico. Ele tampouco comparece à coletânea organizada pelos colegas e amigos de Pollak com o título Une Identité Blessé. Études de Sociologie et diHistoire, publicada um ano depois de sua morte. Daí porque ao leitor familiarizado com esse percurso autoral pode parecer pertinente explicar a razão pela qual os editores e a tradutora escolheram, da sua vasta produção ainda inédita em português, esse que figura como o mais raramente citado dos artigos que Pollak publicou entre a defesa da tese de doutorado, em 1975, e o começo da década de 1990, quando dividia seu tempo entre o IHTP e o Grupo de Sociologia Moral e Política da EHESS.

Deixando temporariamente de lado o mérito heurístico dessa produção, nossa resposta desvia de uma visão retrospectiva que nos impeliria a situar o artigo ora apresentado no conjunto da obra, isto é, enquanto parte de um legado textual coerente nas relações que os textos mantém entre si e com a trajetória do autor. $\mathrm{Na}$ verdade, a decisão se apoia em outro artifício, mais difícil e desafiador: o de abolir a distância que nos separa do momento em que o texto foi escrito para, aproximando-nos da originalidade metodológica de Pollak e da clarividência política de Kraus (estando ambas ancoradas na tensão fecunda entre implicaçáo pessoal e distanciamento crítico), apontar os efeitos nefastos acarretados pelos usos "interesseiros da linguagem".

Vale lembrar então que o texto, publicado em 1981, provém de um Pollak de 31 anos, doutor desde os 27 , há dez anos radicado em Paris e 
que apenas no ano anterior finalmente superara as dificuldades que vinha enfrentando desde 1976 para se integrar ao universo institucional da pesquisa em ciências sociais na França. De acordo com o testemunho emocionado do ex-orientador, Pierre Bourdieu, o artigo responde a uma daquelas situações em que as solicitações internas ditavam as orientaçóes utópicas do trabalho de Pollak: fazer com que o conhecimento interviesse sobre a realidade.

"Tínhamos em comum uma admiração imensa por Karl Krauss, cujos combates nos pareciam constituir um exemplo da contribuição que um intelectual critico poderia dar para mudar o mundo, notadamente mudando as palavras empregadas para nomeá-lo, ou declarando guerra aos que empregam palavras a torto e a direito, como faz um certo jornalismo" (Bourdieu, 1992). Ciente dos riscos que a profissão de intelectual implica, Pollak, com esse artigo, dobrava a aposta, dando prosseguimento aos combates de seu protagonista por outros meios.

O resultado é um texto simples, em certos aspectos quase informe, mas estruturado de maneira complexa. Simples no tom reto e direto; informe no vocabulário restrito, na sintaxe repetitiva, na escassez de conectores e no abuso de fórmulas linguísticas bem conhecidas, do tipo “c'est comme si...". Mas é também uma sociologia histórica com semblante jornalístico, que lança mão de fotografias e caixas de texto (tradicionalmente adotadas pela $A R S S)$, onde são comuns flashbacks e prognósticos retrospectivos, com o emprego dos modos verbais correspondentes, mais que perfeito e futuro do pretérito. Tais características, somadas à relativa incompetência técnica de uma dublê de tradutora, intensificaram a refrega da historiadora com o original. No entanto, mais do que isso, foram a têmpera do personagem, a plausibilidade do argumento e a similitude do caso analisado com outras situaçóes-limite (por exemplo, as nossas ditaduras) que fizeram da tradução um desafio internamente perturbador. Com a esperança de que a perturbação se deva menos ao texto do que à leitora, a escolha de traduzir este e não qualquer outro artigo de Michel Pollak se nutre da expectativa de que ele venha a intervir sobre a nossa própria realidade política, suscitando perspectivas responsáveis de análise sobre a atual configuração discursiva do debate cívico brasileiro. 


\section{Referências}

BAstiN, G. Identités de Michael Pollak. Le Monde, 5 jun. 2018. Disponível em: <https://www. lemonde.fr/livres/article/2008/06/05/identites-de-michael-pollak_1053976_3260.html>. Acesso em: 6 set. 2018.

BÉDARIDA, F. Préface. In: POLLAK, M. Une identité blessée. Études de sociologie et d'histoire. Paris: Métailié, 1993. p. 9-11.

BOURDIEU, P. Michael Pollak. Gai Pied Hebdo, n 525, jun. 1992. Disponível em: <http:// www.homme-moderne.org/societe/socio/bourdieu/varia/pollak92.html\#Marie-Ange\%20Schiltz>. Acesso em:

ISRAËL, L. e VOLDMAN, D. V. (Dir.). Michael Pollak. De l'identité blessée à une sociologie des possibles. Paris: Editions Complexe, 2008.

POLLAK, M. Vienne 1900. Une identité blessée. Paris: Gallimard, 1984.

L'Expérience concentrationnaire. Essai sur le maintien de l'identité sociale. Paris: Métailié, 1990.

POLLAK, M.; HEINICH, N. M. Le Témoignage. Actes de la Recherche en Sciences Sociales, jun. p. 3, 1986. 